\title{
LA PROFECÍA MEDIEVAL EN LA LITERATURA CASTELLANA Y SU RELACIÓN CON LAS CORRIENTES PROFÉTICAS EUROPEAS
}

Las profecías medievales proceden de la literatura bíblica, unas veces de sus vaticinios y pronósticos, otras de los comentarios de los intérpretes. Las Sagradas Escrituras, al presentar a Israel como el elegido entre los pueblos, le habían asegurado un extraordinario futuro, una función destacada en la historia remota de los hombres ("Populus autem tuus omnes iusti; in perpetumm haereditabunt terram": Isaías, 60:21) ${ }^{1}$. Habían afirmado que su triunfo se vería precedido por sufrimientos y catástrofes: sufrimientos para purgar las ofensas hechas al Señor, catástrofes para certificar la penitencia, para anunciar el momento en que el reino de Dios había de establecerse en el mundo. Reino éste sin límites temporales y sin fronteras espaciales, en el que Israel gozaría de la majestad y del dominio: "Regnum autem, et potestas, et magnitudo regni, quae est subter omne caelum, detur populo sanctorum Altissimi" (Daniel, 7:27). Las Sagradas Escrituras describen ese momento sin escatimar hipérboles ponderativas: en él se realizarán toda clase de imposibles y quimeras, reinarán la paz y la justicia, la inocencia, la felicidad y la sabiduría (cf. Isaías, 11:1-9) .

Estas afirmaciones, que continúan entre las comunidades judías de la diáspora, caracterizan también a los grupos cristianos de los primeros siglos. Necesitados éstos de un sostén que les apoyara, lo buscan y lo encuentran en el Apocalipsis; porque el Apocalipsis prometía la destrucción de sus perseguidores, la caída de Roma y del imperio (18:10: "Vae, vae civitas illa magna Babylon, civitas illa fortis, quoniam una hora venit iudicium tuum"). Prometía además la aparición del Anticristo y su derrota, prometía el encarcelamiento del demonio durante mil años de santidad y de justicia (19:20-20:2) y, aunque aseguraba su liberación para después del milenario, anunciaba también la segunda venida del Mesías, el juicio final y el reino glorioso de la Jerusalén celeste (20:7-21:2). En-

1 Utilizaremos a lo largo de nuestro trabajo la Biblia Vulgata de la Biblioteca de Autores Cristianos, Madrid, 1959. 
contraban los cristianos en el Apocalipsis, por lo tanto, una cantera prodigiosa de esperanza y de energía; de ahí que los vaticinios se apresurasen a mantener su patrón y sus elementos, de ahí también que insistieran los comentadores en explicar literalmente sus palabras y en atribuir a las escrituras bíblicas su significado y su sentido. Se alude con frecuencia a una serie de desgracias y de persecuciones, $\mathrm{y}$, en pugna con los judíos, se interpretan las palabras de los profetas como si estuvieran dirigidas a los cristianos. Afirma San Justino, por ejemplo, en relación con una de las profecías de Miqueas: "Cada cristiano es expulsado no sólo de sus propias posesiones, sino del mundo entero, pues a ninguno le consentís [dice a los judíos] el derecho a la vida. Vosotros, sin embargo, decís que eso ha sucedido a vuestro pueblo"'2. Se alude también a la caída de Roma y a la aparición del Anticristo ("Los hombres se aborrecerán los unos a los otros, y se perseguirán y traicionarán", dice la Didaché en el siglo primero, "y entonces aparecerá como hijo de Dios el extraviador del mundo, y realizará milagros y prodigios, y la tierra será entregada en sus manos") ${ }^{3}$. Se insiste sobre todo en la llegada del milenio, en los mil años en que Cristo y sus seguidores reinarán en la Jerusalén terrena con felicidad y justicia. Frente a los ataques de Trifón, afirma San Justino: "No sólo admitimos la futura resurrección de la carne, sino también mil años en Jerusalén, reconstruida, hermoseada y dilatada como lo prometen Ezequiel, Isaías y los otros profetas"4. Se alude al juicio final y a la venida del Mesías, y sin vacilación se insiste en su inminencia. "Cerca está el día en que todo perecerá", asegura el pseudo-Bernabé, y proclama San Clemente en la segunda de sus epístolas: "Conoced que llega ya el día del juicio [...] y algunos de los cielos se derretirán, y toda la tierra será como plomo derretido"'.

2 Padres apologistas griegos, trad. Daniel Ruiz Bueno, Madrid, 1954 (BAC, 116), p. 494.

3 Padres apostólicos, ed. y trad. Daniel Ruiz Bueno, Madrid, 1967 (BAC, 65), p. 93. La epístola del pseudo-Bernabé (ibid., p. 776) presenta, en las postrimerías de la primera centuria, la destrucción de Roma como inmediata al identificar con el imperio el cuarto reino de la famosa profecía de Daniel (Daniel, 7). Véase lo que, en relación con esta profecía, decimos al hablar de San Agustín.

4 Padres apologistas griegos, p. 447. Transcribe así San Jerónimo la pregunta de Trifón: "¿Realmente confesáis vosotros que ha de reconstruirse la ciudad de Jerusalén, y esperáis que allí ha de reunirse vuestro pueblo y alegrarse con Cristo, con los patriarcas y profetas y los santos de nuestro linaje y hasta los prosélitos anteriores a la venida de vuestro Cristo, o es que viniste a parar a esa conclusión sólo por dar la impresión de que nos ganabas de todo punto en la discusión?" (pp. 445-446). San Justino mantiene aquí las afirmaciones de San Ireneo; el cual, a su vez, repite y conserva las que Papias había formulado (Padres apostólicos, pp. 871-872).

5 Padres apostólicos, p. 809.

6 Ibid., p. 368. Téngase en cuenta, sin embargo, que la epístola, al parecer, 
Sin embargo, al compás que triunfa la nueva religión sobre el imperio, y al compás que éste la acepta y la asimila, los vaticinios y las interpretaciones se van modificando. La influencia grecolatina es más fuerte, por de pronto; se acude a menudo a Horacio y a Virgilio. No se alude tanto a la caída del imperio, se promete o se exalta su victoria; una victoria nueva, en la que los mártires sustituyen a los conquistadores y a los césares. Afirma así Prudencio jubiloso:

Antiqua fanorum parens, iam Roma Christo dedita, Laurentio uictrix duce ritum triunfas barbarum? ${ }^{7}$.

Se puede anticipar así la venida de un príncipe nuevo: él purificará las costumbres, destruirá los ídolos e introducirá el cristianismo en el imperio. Roma, con él, resplandecerá más gloriosa; y hasta los mármoles paganos que la ensuciaban y empequeñecían, aumentarán y sublimarán entonces su esplendor y su belleza (ibid., p. 514):

Video futurum principern quandoque, qui seruus Dei, teatris sacrorum sordibus seruire Roma non sinat [...].

Tunc pura ab omni sanguine tandem nitebunt marmora stabunt et aera innoxia, quae nunc habentur idola.

Esta figura (es decir, la de un príncipe regenerador), que reúne motivos bíblicos y romanos 8 , y que con Prudencio se destaca, se repetirá frecuentemente en adelante con nuevas características y con nuevos propósitos. En los momentos de decadencia fomentará la reforma, animará en los períodos de peligro, capitaneará a los justos en el soñado milenio. Se identificará con ella a príncipes y a reyes, y príncipes y reyes con sus proezas intentarán representarla. Se enriquecen, así, los vaticinios y cambian hasta cierto punto su significado.

no pertenece a San Clemente, ya que debe de ser posterior en unas décadas a la muerte del santo.

7 Peristephanon, himno II. Cito por la ed. de Obras completas, Madrid, 1950 (BAC, 58), p. 488.

8 Se relaciona por una parte con el príncipe que aparece en muchos de los profetas (en Daniel y en el Apocalipsis, por ejemplo); se relaciona también con el que viticinaron a menudo los autores latinos (con el de la Égloga IV de Virgilio por ejemplo, y con el que aparece en la profecía de Anquises en el libro VI de la Eneida). 


\section{San Agustín y San Gregorio}

Es San Agustín el que resume mejor los nuevos ideales, el que al sostener en ellos su concepción de la historia, los expresa con una precisión más evidente. Es verdad que aún presenta como razonables ciertas interpretaciones que refieren a Roma alguna profecía: cuando enuncia, por ejemplo, la opinión de San Jerónimo sobre los cuatro reinos que, según el Libro de Daniel, debían preceder al Anticristo $^{9}$, o cuando alude a los que encontraban referencias a la destrucción de Roma en la epístola de San Pablo a los tesalonicenses $^{10}$. No comparte, a pesar de todo, aquellas opiniones: indica los motivos que le impiden aceptarlas o las rechaza sin reserva ${ }^{11}$. Rechaza, por ejemplo, las que atribuían a Roma la maternidad del Anticristo, y esperaban (identificándole con Nerón) que apareciera de nuevo': "Multum mihi mira est haec opinatium tanta praesump-

9 En el Libro de Daniel (7:17-24), el personaje que explica la profecía dice: "Hae quatuor bestiae magnae quatuor sunt regna quae consurgent de terra. Suscipient autem regnum sancti Dei altissimi, et obtinebunt regnum usque in saeculum, et saeculum saeculorum [...]. Bestia quarta, regnum quartum erit in terra, quod maius erit omnibus regnis; et devorabit universam terram $[\ldots]$. Porro cornua decem ipsius regni, decem reges erunt; et alius consurget post eos, et ipse potentior erit prioribus, et tres reges humiliabit". Y comenta San Agustín, La ciudad de Dios, XX, 23, ed. Madrid, 1958 (BAC, 171-172), p. 1509: "Quatuor ella regna exposuerunt quidam Assyriorum, Persarum, Macedonum, et Romanorum. Quam vero convenienter id fecerint, qui nosse desiderant, legant presbyteri Hieronymi librum in Danielem, satis diligenter eruditeque conscriptum".

1.0 San Agustín, ibid., XX, 19 (ed. cit., p. 1492): "Illud tamen quod ait Apostolus, «Tantum qui modo tenet teneat, donee de medio fiat»; non absurde de ipso Romano imperio creditur dictum".

11 Dice así en relación con la primera, al no encontrar entre los romanos ios diez reyes que la profecía necesitaba: "Vererime sane fateor, ne in decem regibus, quos tanquam decem homines videtur inventurus Antichristus, forte fallamur, atque ita ille inopinatus adveniat, non existentibus tot regibus in orbe romano" (ibid., p. 1510); y en relación con la segunda, antes de presentar las diversas interpretaciones de la epístola de San Pablo: "Ergo prorsus quid dixerit, me fateor ignorare. Suspiciones tamen hominum, quas vel audire, vel legere potui, non tacebo" (ibid., p. 1491)

12 Dice San Agustín antes inmediatamente de la cita que sigue en el texto: "Quidam putant hoc de imperio dictum fuisse Romano; et propterea Paulum apostolum non id aperte scribere voluisse, ne calumnian videlicet incurreret, quod Romano imperio male optaverit, cum speraretur aeternum: ut hoc quod dixit, "Iam enim mysterium iniquitatis operatur", Neronem voluerit intelligi, cuius iam facta velut Antichristi videbantur. Unde nonnulli ipsum resurrecturum, et futurum Antichristum suspicantur. Alii vero nec occisum putant, sed subtractum potius, ut putaretur occisus; et vivum occultari in vigore ipsius aetatis, in qua fuit, cum crederetur exstinctus, donee suo tempore reveletur, et restituatur in regnum" (ibid., pp. 1491-1492). Estas interpretaciones, que San Agustín rechaza, llevaron a la creación de una figura que permitió identificar 
tio". Niega, por de pronto, el sentido literal de las profecías, pero afirma, sin embargo, la significación alegórica de éstas. Puede, por eso, rechazar lo que sobre el milenio se había asegurado: "Algunos se esfuerzan -dice- en relacionar con el milenio aquellas palabras [de Isaías, 65:19: "Yo gozaré en Jerusalén y me alegraré de mi pueblo»]. Se mezclan, en realidad, a manera profética, locuciones propias y figuradas para que el esfuerzo sobrio, a través de un trabajo útil y saludable, llegue al sentido espiritual. Con todo, la pereza de la carne, o la estupidez de la mente ignorante y sin experiencia, cree, satisfecha con lo externo de las palabras, que no se debe buscar el sentido interior"'13. Le es posible entonces atribuir un carácter espiritual al milenio ${ }^{14}$, y presentar a éste, no como una ilusión remota que se espera, sino como una realidad que en el presente se efectúa. Período que transcurre entre las dos venidas del Mesías, porque la Iglesia nace con él y con él se desarrolla, porque a través de ésta el reino espiritual de Cristo se establece en el mundo ${ }^{15}$. Se pone en la Jerusalén celeste el énfasis que se ponía en el milenio, y además se la convierte en meta del destino y de la esperanza de los hombres: "Ibi vacabimus, et videbimus; videbimus et amabimus; amabimus et laudabimus. Ecce quod erit in fine sine fine. Nam quis alius noster est finis, nisi pervenire ad regnum, cuius nullus est finis?"16 Busca San Agustín de esa manera apartar de los objetivos contingentes la voluntad y los sentimientos de los hombres, para poder encaminarlos hacia unos objetivos transcendentes más altos y operantes: "Cives sanctae civitatis Dei $[\ldots]$ metuunt cupiuntque, dolent gaudentque [...]. Metuunt poenam aeternam, cupiunt vitam aeternam [...], dolent in peccatis, gaudent in operi-

con el Anticristo a los monarcas; figura opuesta y paralela al príncipe que en Prudencio señalamos, y que se transmitió con el apoyo de dos intervenciones que al rey se prometían: una que concluía con su ocultamiento o con su muerte y otra que después de su reaparación se efectuaba.

13 Ibid., XX, 21 (ed. cit., pp. 1501-1502): "Quae quidam ad carnales illos mille annos referre conantur. Locutiones enim topicae propriis prophetico more miscentur: ut ad intellectum spiritualem intentio sobria cum quodam utili ac salubri labore perveniat: pigritia vero carnalis, vel ineruditae atque inexercitatae tarditas mentis contenta litterae superficie, nihil putat interius requirendum".

14 No es San Agustín, sin embargo, el primero que defiende la interpretación alegórica. La epístola del pseudo-Clemente atribuye, a principios del siglo Ir, un sentido espiritual al milenio (Padres apostólicos, pp. 364-365). En la misma centuria Trifón rechaza la teoría literal oponiéndose a San Justino (véase nuestra nota 4), y a comienzos del siglo iv la rechaza Eusebio oponiéndose a Papias (Padres apostólicos, p. 876).

15 Dice San Agustín, op. cit., XX, 9 (ed. cit., pp. 1465-1466) : "Interea dum mille annis ligatus est diabolus, sancti regnant cum Christo etiam ipsis mille annis eisdem sine dubio [...]. Ergo Ecclesia et nunc est regnum Christi, regnumque caelorum. Regnant itaque cum illo etiam nunc sancti eius".

16 Ibid., XXII, 30 (ed. cit., p. 1722). 
bus bonis"'17. La Jerusalén celeste sustituye así a la Jerusalén terrena en el campo de las aspiraciones humanas. San Agustín otorga al juicio final, por eso, una atención muy grande; escribe todo un libro para explicarlo ${ }^{18}$, y sostiene sus explicaciones con testimonios del Antiguo y del Nuevo Testamento. Afirma ahora, con beligerancia incluso, el sentido literal de las Sagradas Escrituras ("Puesto que vamos a hablar del juicio final, y a asegurar contra los impíos y los incrédulos su existencia, debemos primero fundamentar en testimonios divinos nuestras afirmaciones. Aquellos que no quieren creerlos [...] insisten en que los testimonios de las Sagradas Escrituras tienen un significado distinto") ${ }^{19}$; no abandona, sin embargo, las directrices que le caracterizaban, puesto que atribuye un sentido alegórico a casi cada uno de sus elementos. El énfasis que el juicio final recibe entonces está determinado sobre todo por la función que se le asigna: es puente y eslabón, a ello se debe su importancia; es camino universal y necesario; como camino importa, no importa como meta: "Quoniam per iudicium transibunt ad illos boni, ad istos mali" 20 . Precisamente norque lo concibe como paso, suaviza San Agustín los elementos terroríficos. De ahí que no se acentúe su proximidad y que se acentúe su distancia; de ahí que no se describa el fin del mundo, y que se atribuya un sentido alegórico a las señales con que lo anticipan los profetas ${ }^{21}$. Es cierto que insiste aún en su dramática trascendencia, pero es en su trascendencía en lo que insiste. De ahí que al terminar su comentario abandone el patrón que el Apocalipsis le ofrecía; que no concluya, como aquél, con amenazas, que concluya con esperanza y con consuelo: "Enjugará Dios las lágrimas de sus ojos; y no habrá ya muerte, ni luto, ni llanto, ni dolor"22.

17 Ibid., XIV, 9 (ed. cit., p. 941). De ahí que coloquen en el presente la realización de las profecías: "Alligatio diaboli non solum facta est, ex quo coepit Ecclesia [...] dilatari; sed etiam nunc fit, et fiet usque ad terminum saeculi, quo solvendus est" (XX, 8; ed. cit., p. I462).

${ }_{18}$ Me refiero al libro XX de La ciudad de Dios.

19 Ibid., XX, 1 (ed. cit., p. 1438): "De die ultimi iudicii Dei, quod ipse donaverit locuturi, eumque asserturi adversus impios et incredulos, tanquam in aedificii fundamento prius ponere testimonia divina debemus. Quibus qui nolunt credere, humanis ratiunculis falsis atque fallacibus contravenire conantur, ad hoc ut"aut aliud significare contendant quod adhibetur testimonium de Litteris sacris..."

20 Ibid., XIX, 28 (ed. cit., p. 1431).

21 Recuérdese, por ejemplo, cómo para San Agustín la bestia apocalíptica representa a los que disfrazan su maldad con hipocresía, y cómo el fuego que desciende del cielo y consume a los malvados simboliza la firmeza de los elegidos.

${ }^{22}$ La ciudad de Dios, XX, 17 (ed. cit., p. 1487): "Absterget Deus omnem lacrymam ab oculis eorum; et mors iam non erit, neque luctus, neque clamor, sed nec dolor ullus". Se trata en realidad de un versículo, pero no del último, del Apocalipsis (21:4). 
Sin embargo, la postura que adopta San Gregorio unos decenios más tarde permite asegurar que la tradición precedente mantenía su pujanza. No es que resucitara San Gregorio la creencia en los mil años; el concilio de Éfeso se lo prohibía, se lo impedían además lo ascético de su sensibilidad y lo pesimista de su carácter. No busca, pues, anticipar la grandeza del milenio; pero prevé las tribulaciones del futuro. Innumerables circunstancias se lo permitian: la Roma triunfadora sucumbe por fin al empuje de sus enemigos, y un lamento clamoroso acompaña su destrucción y su caída. Recoge San Gregorio mejor que otro cualquiera de sus contemporáneos la angustia de su tiempo; compara, por eso, con una insistencia alucinante y con un dolor que no mitiga su ascetismo, la miseria profunda del presente y la gloria pasada del imperio: "Ipsa autem quae aliquando mundi domina esse videbatur qualis remanserit Roma conspicimus. Immensis doloribus multipliciter attrita, desolatione civium, impressione hostium, frequentia ruinarum"23. Muestra la comparación las penalidades del presente, pero, sobre todo, descubre el origen de esas penalidades e indica su significado. De ahí que se expliquen como instrumento con el que Dios facilita la conversión de los hombres: "Quid est jam [...] quod in hoc mundo libeat? Ubique luctus aspicimus, undique gemitus audimus [...]. Quid est ergo quod in hac vita libeat [...]? Si et talem adhuc mundum diligimus, non jam gaudia, sed vulnera amamus" (ibid., cols. 1009s). Busca San Gregorio, por lo tanto, el arrepentimiento y la enmienda, y aprovecha, para conseguirlo, los argumentos que las circunstancias le ofrecen: "Quid autem terrores quos cernimus, nisi sequentis irae praecones dixerimus?" ${ }_{24}$ Así, pues, lo pavoroso de la catástrofe le permite creer que el fin del mundo se aproxima; de ahí que el presente adquiera ahora, anunciando el juicio y sus horrores, un valor trascendental y una importancia nueva: "Meditad con cuidado en aquel día, corregid la vida, cambiad las costumbres [...], porque veréis venir el eterno juez tanto más seguros cuanto más prevengáis ahora con vuestro temor su severidad"25. Aproxima, por eso, el fin del mundo; lo coloca, no como San Agustín en una lejanía desdibujada, sino en un futuro inmediato y cercanísimo: "Despiciamus ergo $[\ldots]$ hoc praesens saeculum vel exstinctum; finiamus mundi desideria saltem cum mundi fine" Se atribuye al fin del mundo, por lo tanto, un sentido diferente del que San Agustín le había atribuido; se le continúa viendo como

23 Homiliae in Ezechielem, lib. II, homil. vi, 22, en PL, t. 76, col. 1010.

24 Homiliae in Evangelia, lib. I, homil. I, 6 (ed. cit., col. 1081).

25 Ibid.: "Illum ergo diem $[\ldots]$ tota intentione cogitate, vitam corrigite, mores mutate [...]. Adventum namque aeterni judicis tanto securiores quandoque videbitis, quanto nunc districtionem illius timendo praevenitis".

${ }^{26}$ In Ezechielem, II, vi, 24 (ed. cit., col. 1011). 
paso, pero importa sobre todo lo que tiene de meta ${ }^{27}$. Importa su llegada, porque con su llegada la conversión se facilita; y en su llegada insiste San Gregorio: "El mundo en años anteriores fue vigoroso en juventud [...], pero se ve ahora debilitado por la vejez y casi empujado a la muerte, ya vecina, por sus enfermedades crecientes. No queráis amar, por lo tanto, al que no puede durar mucho"'28. Busca por eso San Gregorio las señales que deben preceder al último momento, y porque cree en el sentido literal de las Sagradas Escrituras ${ }^{29}$, las busca literalmente en las circunstancias de su época: "Anuncia Nuestro Redentor [en el Evangelio] las calamidades que tendrán lugar cuando termine este mundo ya casi terminado [...]. Vemos que algunas han ya sucedido, tememos que las otras sucederán muy pronto. Por ejemplo, hemos visto en nuestro tiempo, más que en las crónicas antiguas, que unas gentes se levantan contra otras; sabéis cómo oímos hablar a menudo de terremotos que destruyen ciudades; y nosotros, sin descanso, sufrimos epidemias. Es verdad que no hemos visto señales prodigiosas en el cielo, pero colegimos, por los cambios de la atmósfera, que incluso éstas no están lejos de nosotros" ${ }^{30}$.

En resumen, podemos afirmar que el fin del mundo acorta con San Gregorio la distancia que se le había atribuido, que se acerca con él al horizonte humano, y que en el horizonte humano comienza a realizarse. Los intérpretes de las Sagradas Escrituras imitaron después a San Gregorio y repitieron a menudo sus teorías. Se explica así su influencia extraordinaria. Con él se relaciona la fórmula "appropinquante mundi termino" que resumirá durante muchos años la actitud escatológica corriente: "Jam mundi gloriam stravit -había afirmado San Gregorio-, jam ruinis ejus crebrescentibus, districti sui judicii diem propinquantem denuntiat", ${ }^{11}$.

Pueden señalarse desde el siglo $\mathrm{v}$, por lo tanto, dos actitudes

22 In Evangelia, I, 1, 3 (ed. cit., col. 1080): "Fructus mundi ruina est. Ad hoc enim crescit, ut cadat. Ad hoc germinat, ut quaecunque germinaverit, cladibus consumat".

28 Ibid.: "Ita mundus in annis prioribus velut in juventute viguit [...], at nunc ipsa sua senectute deprimitur, et quasi ad vicinam mortem molestiis crescentibus urgetur. Nolite ergo [...] diligere quem videtis diu stare non posse".

29 Cree también, como San Agustín, en el alegórico.

30 In Evangelia, I, 1, 1 (ed. cit., cois. 1077 y 1078): "Dominus ac Redemptor noster [...] senescentem mundum quae mala sequantur denuntiat [...]. Ex quibus profecto omnibus alia jam facta cernimus, alia e proximo ventura formidamus. Nam gentem super gentem exsurgere, earumque pressuram terris insistere, plus jam in nostris temporibus cernimus quam in codicibus legimus. Quod terrae motus urbes innumeras subruat, ex aliis mundi partibus scitis quam frequenter audivimus. Pestilentias sine cessatione patimur. Signa vero in sole, et luna, et stellis, adhuc aperte minime videmus, sed quia et haec non longe sint, ex ipsa jam aeris immutatione colligimus..."

31 lbid., I, v, 1 (ed. cit., col. 1093). 
ante las viejas profecías: la que les atribuye un sentido espiritual y coloca su realización en el presente, y la que, dándoles un significado literal, dirige hacia el futuro sus pronósticos. Con miras trascendentales la primera, cree comenzado ya el reino místico de Cristo; de ahí que dibuje la Jerusalén celeste para guiar a los hombres y para dirigir sus pasos. La segunda, con miras terrenales unas veces y trascendentales otras, espera una edad feliz y mesiánica o un período de calamidades y miserias; de ahí que dibuje la Jerusalén terrestre para preparar la llegada del milenio o para presentar el fin del mundo con sus tribulaciones y castigos. Esta última actitud, al continuarse, originó una corriente profética poderosa; corriente que adoptó un patrón y unos elementos que, combinados entre sí y modificados, le confirieron flexibilidad e independencia. Aluden generalmente sus profecías a un período de perversión y de tribulaciones al que se hace terminar con la llegada de un príncipe universal y justiciero. De ahí que triunfe sobre los paganos o sobre los musulmanes, de ahí que se le reserve Jerusalén y su conquista, de ahí que se le atribuya la conversión de los judíos. Pero debe terminar también ese momento extraordinario, afirman los pronósticos: Gog y Magog atacan a la Iglesia, y el Anticristo arrastra a los hombres por primera vez o por segunda. Se insiste, sin embargo, en su derrota, y se la hace coincidir con la venida del Mesías; y el Mesías entonces, juzgando a los injustos y a los justos, abriendo la eternidad y cerrando el tiempo, se levanta al fondo de los vaticinios para sostener a los fieles y para respaldar a los profetas.

\section{Las Cruzadas. La pugna entre el. Pontificado y ex. Imperio}

Así como la tradición provee a las profecías de esquemas y de elementos, las circunstancias históricas influyen en la selección de sus materiales y en el ritmo de su desarrollo. Se explica por eso la rapidez con que se extienden durante las Cruzadas: representaron entonces el mejor de los recursos para conseguir una colaboración indispensable. En efecto, al asegurar la conquista de Jerusalén atribuían un especial prestigio al príncipe que la consiguiera, le convertían en el emperador de los pronósticos; a los que venían soportando las injusticias sociales, les aseguraban además una época de reparación y de justicia, el reino esperado y prodigioso de la Jerusalén terrestre. De ahí que nazcan las Cruzadas entre profecías y entre vaticinios. Cuando en 1095 recomienda Urbano 11 la conquista de la Tierra Santa, apoya sus razonamientos en una serie de promesas; promesas de índole espiritual por una parte (el perdón de los pecados y la bienaventuranza futura), de indole material por otra (un nuevo paraíso que enriquecería a los desheredados y que consolaría a los afligidos). Las promesas del pontífice se fortalecie- 
ron con las aún más seductoras de Pedro el Ermitaño; no es de extrañar así ni el carácter popular de la Primera Cruzada, ni la generosidad con que participaron en ella las clases campesinas. Tal fue el aumento de los vaticinios, que las crónicas los incorporan a partir de entonces; intervienen en éstas santos, ángeles y difuntos para animar a los guerreros con sus palabras, para sostenerles en la incertidumbre de la lucha, para afirmar después de la victoria la exactitud de los pronósticos.

Se acude también a las profecías en las Cruzadas posteriores. Al predicar la Segunda, San Bernardo promete a sus ejércitos la destrucción de los enemigos; tiene por eso que justificarse cuando le califican de pseudoprofeta después de la derrota. Durante la Cuarta Cruzada, Folco de Neuilly intentó arrastrar al pueblo aunque no pudo realizarlo; su fracaso no supone, a pesar de todo, un desinterés en relación con las profecías; indica, sí, la actitud diferente de los campesinos hacia las empresas reconquistadoras. Cuando la Cruzada de los Niños, es Étienne, el pastor francés de doce años, quien empuja a éstos con sus visiones y con sus augurios ${ }^{32}$; y es la tradición que vinculaba a la conquista de Jerusalén el dominio del universo, la que, impulsando a Enrique de Inglaterra y al emperador Federico, da lugar a que la Quinta Cruzada se organice. La Sexta logró por fin, aunque de manera sorprendente, lo que tantas voces habían anunciado. En efecto, Federico II consiguió, sin acudir a las armas y a pesar de las excomuniones, la liberación de Jerusalén, y su corona. Muchos vieron por eso en Federico al emperador profetizado, y muchos supusieron que había de comenzar con él una era de paz y de justicia; otros, al verle conseguir sin las bendiciones del pontífice lo que tantos habían pretendido sin éxito, se apresuraron a identificarle con el Anticristo, y a prever para la Iglesia catástrofes y amenazas.

No debe extrañar, por lo tanto, que las mismas profecías se utilizaran en apoyo de intereses políticos y de pretensiones nacionales divergentes. Durante la pugna entre el Pontificado y el Imperio sirvieron para justificar la posición de cada uno de los partidos: a veces identificando al emperador con el monarca universal de los augurios y al pontífice con el Anticristo enemigo de la Iglesia; viendo otras en el emperador al Anticristo, e inventando una figura salvadora, un "Pastor Angelicus" ${ }^{33}$ que permitiera con una nueva identificación el encumbramiento del pontífice. Sirvieron también

32 Etienne no sólo les prometió la conquista de Jerusalén y la victoria, les prometió además toda clase de milagros; por ejemplo, que se abrirían las aguas para facilitar su camino. En esas aguas precisamente perecieron muchos de los cruzados.

33 Esta figura puede encontrarse ya en los epítetos proféticos con que Malaquías, el obispo de Armagh amigo de San Bernardo, aludió a los papas del futuro. 
para legitimar aspiraciones nacionalistas, pues, al investir con los atributos imperiales a algunos de los monarcas, se convertía en el más noble de los reinos a su reino, y, en un plano teórico, se le liberaba de intromisiones extranjeras. Se utilizaron también las profecías para animar a los pueblos en sus momentos críticos, y se explicaron entonces las catástrofes como anuncio de su futura gloria. Defienden con frecuencia a los monarcas de los usurpadores, y exigen a favor de aquéllos el respaldo de los súbditos; otras veces, por el contrario, justifican la rebeldía, y buscan para el usurpador la colaboración del pueblo. Sirven también de apoyo a los teóricos en su función reformadora, proveyendo de nuevos objetivos a los doctrinales de príncipes y de nuevos argumentos a los tratados morales. De ahí que pretendan a menudo resolver los problemas del presente; de ahí también que, señalando la perversión y la malicia, y acentuando las calamidades por éstas provocadas, aconsejen una conducta nueva, una renovación positiva.

Las profecías de la Edad Media, por lo tanto, con un origen, unos temas y unos propósitos comunes, disponen de materiales que seleccionan y combinan según las circunstancias históricas en que aparecen. Se pueden distinguir, con todo, dentro de esa uniformidad, núcleos determinados; los cuales, aunque mantienen sus rasgos característicos, presentan a su vez elementos que los individualizan. Es múltiple el origen de esos elementos y múltiple también su carácter; alguno incluso, profético en sí mismo, desciende de culturas extrañas a las profecías que nos interesan; otros, en cambio, son la expresión únicamente de la intensidad con que se desarrollaron ciertos sentimientos o ciertas actitudes. Se distinguen entre los primeros los de un grupo de profecías que se relacionan con la literatura arturiana, y que se construyen en torno al Merlín de las leyendas; se encuentran entre los segundos los que aparecen en los vaticinios que con Joaquín de Fiore, y después con la esperanza en la venida del Espíritu, crecieron y se multiplicaron.

\section{Merlín y Joaquín de Fiore}

Las profecías de Merlín (en relación con fábulas antiquísimas) se desarrollaron en Inglaterra cuando los bretones, a medida que se replegaban ante la invasión anglosajona, necesitaron de una garantía sobrenatural que les sostuviese. Manejan éstas desde el principio un gran número de materiales, y construyen con ellos oscuras alegorías. Se dibuja una amplia y movida plataforma, y se sujetan sus elementos a una transformación constante que modifica su estado o su sustancia: se nivelan los montes con los llanos, y se convierte en sangre el agua de los ríos ("Montes itaque ut eius ualles equabun- 
tur, et flumina uallium sanguine manabunt") ${ }^{34}$, se derrumban y se levantan edificios y ciudades ("Ue genti periure, quia urbs inclita propter eam ruet", p. 391) ; flores, árboles y plantas prosperan para morir y para florecer de nuevo ("Tunc exurget in illum aquilo, et flores quos zephirus procreauit, eripiet", p. 386). Se encadenan, así, mediante su transformación precisamente, circunstancias y elementos: "Formam alterius corporis recipiet. Terra namque in lapides, lapides in limpham, lignum in cineres, cinis in aquam, si superiecta fuerint uertentur" (p. 390). Osos, lobos y jabalíes; toros, ciervos y dragones; leones, asnos y zorras; cisnes, águilas y peces se reúnen, también intercambiando su sustancia, para predecir en cuanto símbolos el futuro de los pueblos ${ }^{35}$. Estrellas y planetas modifican su curso y abandonan la función que hasta entonces habían mantenido; influyen aciagas en los acontecimientos, determinan maléficas el destino de los hombres: "Ab eis uultus auertent sidera, et solitum cursum confundent [...]. Splendor solis electro mercurii languebit, et erit horror inspicientibus" 36 . El reino animal, el vegetal y el mineral, la geografía y la astronomía se emplean, por lo tanto, para construir un paisaje alegórico en el que el futuro se proyecta y se ilumina. El carácter de las profecías se adecúa sin dificultad a ese panorama multiforme: presentan los símbolos, mediante la transformación y el cambio, extensos catálogos de reyes, series infinitas de sucesos $^{37}$. Imprime la historia así una amplitud insospechada a

${ }^{34}$ Seguimos el texto que Godofredo de Monmouth interpola en su Historia Regum Britanniae, porque su origen anterior parece seguro. Utilizamos la edición de Acton Griscom. London-New York-Toronto, 1929. Esta primera cita se encuentra en la p. 385.

35 "Tria oua procreabuntur in nido, ex quibus uulpes et lupus et ursus, egredientur (p. 392). "Peribit miluorum rapacitas, et dentes luporum hebetabuntur" (p. 387). "Exin transuertet sese in aprum, et quasi sine membris expectabit germanos" (p. 393). "Nascentur inde tres tauri fulgurantes, qui consumptis pascuis conuertentur in arbores" (p. 395) . "Interficiet eam ceruus $x$ ramorum" (p. 391). "Egressi sunt duo dracones, quorum unus albus, et alius rubeus. Cumque alter alteri appropinquasset, commiserunt diram pugnam" (p. 384). "Catuli leonis in equoreos pisces transformabuntur" (p. 387). "Succedet asinus nequicie in fabricatores auri uelox" (p. 390). "Interim descendet uulpes de montibus, et sese in lupum mutabit" (p. 392). "Fauille rogi mutabuntur in cignos, qui in sicco quasi in flumine natabunt" (p. 393). "Aquila eius super montem arauium nidificabit" (p. 387). "Pisces illius calore morientur. Et ex eis procreabuntur serpentes" (p. 390).

36 Ibid., p. 397. E1 texto continúa así: "Mutabit clipeum stilbon, archadie, uocabit uenerem galea martis. Galea martis umbram conficiet, transibit terminos furor mercurii. Nudabit ensem orion ferreus. Uexabit nubes phebus equoreus. Exibit iupiter licitas semitas, et uenus deseret statutas lineas. Saturni sideris liuido corruet".

37 Ibid., pp. 385-388: "Set et posteri eius sequentur sceptrum, et post ipsos exurget germanicus uermis [...]. Tunc infortunium albi festinabit, et edificia ortulorum eius diruentur. Septem sceptrigeri perimentur, et unus eorum sanctificabitur [...]. Rex benedictus parabit nauigium, et in aula duodecimi inter 
su cauce, a su movimiento un ritmo vertiginoso, una vibración distinta.

Las profecías de Merlin pasaron al continente, y, al contacto con la tradición profética europea, constituyeron dentro de ésta un nuevo grupo, en el que se yuxtaponían elementos de las dos tradiciones. El carácter continental de sus orígenes determinaba sus temas y sus propósitos; el influjo bretón, por otra parte, imprimía a su marcha un movimiento nuevo, a su estructura un acento especial y distinto. De ahí que las viejas promesas se oigan con mayor vigor entonces: la de la conquista de Jerusalén ("Apres cele guerre sera [ostez] Jerusalem des mains as paiens") ${ }^{38}$, la del monarca universal ("Aura en sa subjection toute Gaule, Bourgoingne, Ghampaingne, Benuic, et Gannes [...] et toutes les illes de la mer", p. 117), la del pontífice renovador ("Sera esleus un apostoille [...] que touz ceus que il porra trouver [...] qui donnent faus jugement par convoitise d'avoir, il les fera jeter en sa cave [...] et [...] celui apostoille saintefiera et fera grans miracles", pp. 212-213), la del triunfo sobre los sarracenos ("Sera fete la vengeance si cruel que jusques as jors de leur vies ne se resourdront les Aufriquans", p. 127). De ahí que aparezcan también las profecías que aseguraban la derrota de los invasores y la victoria de los oprimidos, el triunfo sobre los tiranos y la resurrección de estirpes despojadas ("Il sourdra une guerre [...] que ce sera pour .ii. orphelins du lignage as Lombars, que un quens aura desiretes [...] li orphelins en auront la victore", p. 129); de ahí que se escuchen sin contraposición anuncios de diversas procedencias: los que aseguran con un vocabulario peculiar desastres y calamidades ("Il sera si grant mortalite que la moitie des gens qui seront lors mourront. La terre croulera si desmesureement que ce sera une grant merveille du veoir. L'eve sechera, la terre fera crevaces $[. .$.$] , li soleil et la lune et les estoilles seront en une meismes$ planet", p. 61) y los que avisan con palabras sobrecogedoras el fin del mundo y la aparición del Anticristo ("Li solail sejournera en orient, et la lune en occident, dont jiames ne feront plus leur cours $[\ldots]$, et ce sera signe de finer li monde", p. 326; "Istra un

beatos annumerabitur [...]. Exurget iterum albus draco, et filiam germanie inuitabit [...]. Exinde coronabitur germanicus uermis [...]. Terminus illi positus est quem transuolare nequibit. Centum namque quinquaginta annis in inquietudine et subiectione manebit [...]. Succedent duo dracones [...] succedet leo iusticie, ad cuius rugitum gallicane turres et insulani dracones tremebunt [...]. Catuli leonis in equoreos pisces transformabuntur [...]. Exin de primo in quartum, de quarto in tercium, de tercio in secundum, rotabitur pollex in oleo. Sextus hybernie menia subuertet, et nemora in planiciem mutabit. Diuersas portiones in unum reducet, et capite leonis coronabitur [...]. Egredietur ex eo linx penetrans omnia que ruine proprie gentis imminebit".

3s Les prophecies de Merlin, ed. Lucy Allen Paton, t. 1, New York-London, 1926, pp. 126-127. En las siguientes citas daré en el texto el número de la página. 
mauves dragon iiii. ans devant [que] le dragon de Babilloinne viengne. Celui dragons ira preechant parmi le monde encontre la loy Jhesu Crist si soutivement que li plus sage homme du monde en sera engignies", pp. 61-62).

Las profecias originadas en torno a Joaquín de Fiore, por el contrario, no aportan en realidad nuevos elementos; acentúan algunos precedentes para dirigirse, al influjo de nuevas circunstancias, hacia nuevos objetivos. Reflejan, con todo, así como las doctrinas en que se apoyaron, una conmoción de gran envergadura por el carácter de su amplitud y de su influencia. Dieron principio a un movimiento espiritual que se tradujo en una serie variadísima de manifestaciones, y que se caracterizó, al pretender influir el camino incomprensible de la historia, por lo ambicioso de sus propósitos. Así se explican sus esperanzas mesiánicas y el impulso que éstas imprimieron en las corrientes proféticas tradicionales.

Joaquín de Fiore pretendía sobre todo la renovación de la conducta de sus contemporáneos; cada uno de sus esfuerzos se dirige a conseguirla: muestra, censurando insistente las costumbres de su época, la necesidad de la reforma; indica, prediciendo incansable los sucesos del futuro, la posibilidad de realizarla. No publicó Joaquín sus profecías a pesar de que los papas se lo pidieron; a su muerte, en 1202, las revelaron sus discípulos. Estos, además, decididos a glorificarle (especialmente los franciscanos minoritas), hicieron que predijeran, ampliándolas y retocándolas, muchos de los sucesos anteriores. Es difícil ahora separar de las doctrinas del maestro la colaboración de los discípulos; de ahí que sea necesario para explicarlas aludir al conjunto. Dividen en tres períodos la historia de los hombres: la edad del Padre (o, referida a un apóstol, la de Pedro), que abarcaría desde la creación hasta el nacimiento de Cristo; la del Hijo (o la de Pablo), que llegaría hasta el año 1260; y la del Espíritu (o la de Juan), que en 1260 precisamente había de iniciarse ${ }^{39}$. Afirman también que durante la edad primera los patriarcas guiaron a los fieles, y que los sacerdotes lo hicieron durante la segunda, aunque éstos al final los habían corrompido. Era preciso, por eso, preparar el último período: una orden monástica nueva (pensaban en la suya los franciscanos) restablecería el Evangelio, y un príncipe regenerador gobernaría en el futuro. El Anticristo, sin embargo, debía aparecer, seducir a la Iglesia y destruir su forma tradicional. Sería muy breve, con todo, su victoria; a con-

39 A medida que iban fallando las profecias, se extendía una literatura que las reinterpretaba. Tras el fracaso de 1260, por ejemplo, vuelve sobre los cómputos Ubertino de Casale: atribuye a la segunda edad la duración que Joaquín le había asignado, pero retrasa en treinta y tres años su comienzo (llevándolo a la resurrección de Cristo) para poder fijar en 1293 el del último período. 
tinuación comenzaría el reino del Espíritu, el momento glorioso del amor.

Se asignaban así los franciscanos un papel relevante en el próximo período, y se erigían a la vez en cabeza y en arquetipo de los fieles. De ahí que las censuras contra el clero secular y contra el papa crecieran intensificando lo acerbo de su carácter ${ }^{40}$; de ahí también que los pontífices contestaran muy pronto con una violencia parecida ${ }^{41}$. Así como éstos replican con excomuniones y con castigos, acuden aquéllos, para defenderse, a una tradición profética que a través de un cauce doble se desarrollaba. Niegan a veces la autoridad de los pontífices, y los identifican con el Anticristo para legitimar sus argumentos; justifican, otras, su postura, contrastando a los papas del presente con un pontífice futuro al que presentan como miembro de su orden para acentuar el papel histórico que se venían arrogando. Así se explica la insistencia con que después de Joaquín se ve al Anticristo en los pontífices: a finales del siglo xiII en los que no realizaron la reforma (en Bonifacio VIII más que en ningún otro), en los que persiguieron a los minoritas a principios del XIV (en Juan XXII especialmente), en los que dividieron a la Iglesia al final de la centuria (en Benedicto XIII sobre todo).

De manera semejante, y a través también de esta doble perspectiva, se dibuja a los monarcas. La persona de Federico II, por ejemplo, arrastró poderosamente la atención de sus contemporáneos: la tenacidad de sus empresas, la desmesura de sus propósitos, la mag-

40 Por ejemplo, Pedro Juan d'Olive, jefe de los espirituales de Provenza perseguidos por Juan XXII en 1317, acusando la perversión de las costumbres y afirmando la ilegitimidad de los pontífices, anunció como próximo el castigo, y prometió, para cuando éste se hubiera realizado, una época de santidad que los espirituales dirigirían. También Arnaldo de Vilanova alude a las costumbres de su tiempo; ataca en especial a los grandes y a los eclesiásticos, pero con más vigor condena a los pontífices. Vaticina catástrofes inminentes: el fin del mundo y la aparición del Anticristo; anuncia además sucesos esperanzadores: la llegada de un rey santo y virtuoso ("Aytal princep sera entre crestians apparegut", p. 752), la venida de un papa espiritual, humilde y evangélico ("Suscitara Deus en terra un papa spiritual [...], lo qui ab aytal rey porgara tot crestianisme et tornaral universalment a la veritat primera", p. 752), la conquista de Jerusalén, la conversión de los cismáticos, de los paganos y de los sarracenos ("Promoure la veritat del christianisme per totes parts, ço es entre catholics et scismatichs et pagans [...] continuar entro quell sepulcre de nostre senyor Jhesu Christ sia restituit a Christians", p. 769). Las dos primeras citas pertenecen a una carta que Arnaldo de Vilanova dirigió al rey Jaime II de Aragón, y la tercera al discurso que el mismo Arnaldo pronunció en Avignon ante el papa Clemente $\mathrm{V}$; tanto el discurso como las cartas se encuentran en la Historia de los heterodoxos españoles de Menéndez Pelayo, ed. de Madrid, 1880, tomo 1; a ella se refiere el número de página que indico después de cada una de las citas.

41 Los minoritas perdieron la batalla: perseguidos con insistencia al principio, fueron aniquilados enteramente más tarde. 
nitud de sus victorias, conmovieron durante su vida, y tras su muerte, a partidarios y a enemigos. Le vieron ganar Jerusalén en 1229, y coronarse allí como rey; le vieron, en pugna con la Iglesia, perseguirla, y ser por ella excomulgado y perseguido. No es extraño, por eso, que se le relacionara con los pronósticos de Joaquín y con las profecías anteriores; no es extraño tampoco que se le dibujara de forma diferente y que se le atribuyeran características contradictorias. Así, los espirituales italianos lo identificaron con el Anticristo, viendo en él al perseguidor rencoroso que las profecías aseguraban; los alemanes le identificaron, por el contrario, con el emperador prometido, viendo en él al que debía santificar a la Iglesia y renovarla. De ahí la confusión con que se recibió en 1250 la noticia de su muerte, por lo inesperado del acontecimiento y porque quedaban sin realizar los pronósticos. De ahí también que, para salvarlos, se vaticinara después de la sorpresa la resurrección de Federico. Se le resucitó, en efecto, en Alemania y en Italia; en Alemania como restaurador ilustre de la gloria del imperio, en Italia como símbolo odioso de la maldad y de la injusticia.

\section{Francia}

Las doctrinas de Joaquín y de sus colaboradores influyeron también en los vaticinios franceses y determinaron su desarrollo. Los que aseguraban a un nuevo Carlomagno la conquista de Jerusalén y la corona del imperio, aumentaron al impulso de un sentimiento nacionalista vinculado a la función rectora de la Francia de principios del xiv. Creció con la guerra de los cien años el número de profecías a medida que este sentimiento se ampliaba empujado por invasiones y por derrotas. Ellas reúnen a los súbditos, fortaleciendo a los vacilantes y atrayendo a los indecisos; insistente su voz empuja a la resistencia, y sus afirmaciones apoyan a una dinastía amenazada.

No es de extrañar, por eso, que el franciscano Juan de Roque-

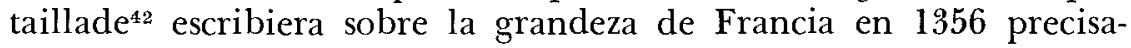
mente; es decir, en la más grave coyuntura del xIv: destruidos los ejércitos franceses y cautivo el soberano. Principia por atribuir a la derrota ecos y referencias universales, la presenta como comienzo de una serie de desgracias infinita, como anuncio de la aparición del Anticristo y de la invasión destructora de los tártaros. De acuerdo con Joaquín, se ven las calamidades como purificación y como penitencia; se asegura, además, que en 1367 comenzará un período presidido por un pontífice y por un monarca: el "Pastor Angelicus"

42 En España se le conoció con frecuencia bajo los nombres de Peratallada, Rupescissa y Rocacisa. 
renovador y minorita, y un rey francés conquistador y, por sus virtudes, franciscano. Ellos vencerán a los infieles y los convertirán, porque al rey se reserva el universo, y al pontífice una Iglesia sin divisiones y sin enemigos.

Continuaron en Francia, pues, las profecías manteniendo la misma dirección y defendiendo los mismos propósitos. Su curso da forma a las inquietudes contemporáneas: señala el camino sorprendente de la guerra de los cien años, y dibuja en las postrimerías del xIv los altibajos del cisma. Se explican las calamidades como consecuencia de los pecados humanos, se enumeran los crímenes, y se ofrecen medios de reparación y de reforma. Para que se escuchen los consejos se insiste en la proximidad de unos castigos aún más trágicos y amenazadores. Se anuncia, así, la venganza de Dios y su justicia: "Le temps vient que li Dieux de nature / qui plus ne puet soufrir la chose tele, / envoyera sur toute creature / larmes de sang et vengence cruele" ${ }_{43}$; se anuncia el fin del mundo de manera parecida: "Je voy la fin de ce monde aprouchier, / selon le dit de la Sainte Escripture" (ibid., t. 3, pp. 153-154); se anuncia también, y como consecuencia, al Anticristo: "Puis doit Antecrist apparoir, / que le monde approuche sa fin" (ibid., t. 5, p. 227).

Los vaticinios, asi, a la vez que muestran un futuro desconsolador y calamitoso, dirigen a los hombres en la doble proyección de su camino: orientando su conducta individual por una parte, y guiando, por otra, su conducta colectiva. Pero además, al predecir un futuro prometedor y venturoso, dibujan, también en doble proyección, al soberano: atribuyéndole las hazañas vaticinadas en los pronósticos, y reservándole la renovación espiritual de sus vasallos:

Puis que je voy né le filz de l'enfant selon les diz et exposicions des prophetes et Sebile qui sent par esperit les grans evencions, de ce monde les tribulacions doivent fenir, et soubz le petit né doit reflourir saincte religions, qu'ainsi est il pieça predestiné.

Fleur qui de fleur pure et nette descent sera de Dieu la vraie elections, qui doit porter son ceptre en Orient, du remanent des persecucions, du regne saint la consecracions; Jherusalem, la sera couronné,

43 Eustache Deschamps, Oeuvres complètes, Paris, 1878-1903, t. 7, p. 114. He elegido a Deschamps para ilustrar estas afirmaciones por ser coetáneo de los poetas de Castilla que a continuación estudiaré, y por haber influido, a mi parecer, en algunos de ellos. 
et soubzmettra payennes nascions, qu'ainsi est il pieça predestiné ${ }^{44}$.

Los vaticinios no se limitan a ennoblecer al príncipe, con todo; ennoblecen también la dinastía que Inglaterra por entonces menoscaba. Aseguran su origen carolingio, y, para reforzar sus argumentos, lo identifican además con Carlomagno: "C'est le roy Charlemaine", afirman insistentes. La línea sucesoria, noble ya por su origen y por su recorrido, se interna en un porvenir glorioso y admirable. En el rey se unen, por eso, el pasado y el futuro: el pasado, para anticipar la grandeza del príncipe con su prestigio; el futuro, para asegurar, con la certidumbre de su realización, la grandeza de Francia (ibid., t. 6, p. 70):

Charles premier sera puissant et fort et le second l'empire d'Alemaigne doit obtenir, et porter son ensaigne sur sarrasins, et cculs doit subjuguer; Jherusalem doit faire premeraine et conquerir la terra d'oultre mer.

\section{Castilla}

Siguen un curso parecido las profecías castellanas; sin embargo, durante mucho tiempo apuntan hacia una sola meta: la continuación y la terminación de la reconquista. Nacieron con el empuje mahometano al compás que los asturleoneses intentaban recuperar los territorios perdidos. Las más antiguas crónicas latinas certifican y aseguran su existencia: prevé Pelayo, en la Chronica Visogothorum, la recuperación de España, y anticipa la expulsión de los invasores la Chronologia et series Gothicorum regum ("Dum praedestinatio usque divina dehinc eos expelli crudeliter jubeat": $P L$, t. 83, col. 1118). Recogen también el Toledano y el Tudense vaticinios que aseguran la victoria a los reyes de Castilla; y a menudo los

44 Ibid., t. 5, p. 288. Es fácil reconocer aquí la influencia de la Egloga IV de Virgilio. De la misma manera utiliza Deschamps los materiales que las profecías de Merlin le deparaban. Puede verse, por ejemplo, la composición que transcribimos (t. 7, pp. 244-245): "Or est le Bruth concordant a Sebile / es granz palus et ou lac des Frommis / que Breuth n'aroit plaine, reçoit ne ville / par le Lion dont ilz sont ennemiz, / puis que le Cerf Volant les avra mis / ains xiiii ans a grant confusion. / L'Asne Pesant sauldra hors d'Albion; / d'un des costez courra la fourmiere; / combatre doit encontre le Lion: / la doit Bruthus estaindre sa banniere [...]. // Le mauvais sang la doit estre peris, / le Cerf Volant en doit eschaper vis; / l'Asne Pesant querra sa region / pour reposer, mais en l'invasion / du Cerf Volant saudra de sa bruiere, / le corps perdra, terre et possession: / la doit Brutus estaindre sa banniere". 
repite Afonso el Sabio: al explicar, por ejemplo, la batalla de Clavijo ("Adurmióse el rey don Ramiro, et appareciól [...] ell apóstol sant Yague et díxol: «... Tú uençrás cras en la mannana»") o al referir más adelante la toma de Coimbra ("Abriré yo cras a ora de tercia la çibdad de Coymbria -dice el apóstol de nuevo-, et darla e al rey don Fernando") ${ }^{45}$. Los documentos literarios guardan también ejemplos y testimonios: el arcángel San Gabriel promete al Cid, en el Poema, un triunfo sin derrotas ("Cavalgad, Ģid, el buen Campeador [...], / mientra que visquiéredes bien se fará lo to") ${ }^{46}$; y prometen al Conde, en el Fernán González, San Millán y San Pelayo el triunfo sobre los sarracenos, bien empujándole a comenzar la lucha ("Farás grrandes batallas en la gent descreyda [...], / cobrrarás de la tierra vna buena partyda"), bien animándole con promesas de milagros y prodigios ("Avn te dize más el alto Criador [...]: / mándate que te vayas lidiar con Almoçor. // Yo seré y contygo, quem' lo ha ortogado, / y será el apóstol Santyago llamado"), bien exponiendo incluso la forma del ataque y la estrategia ("[A] todo el tu pueblo fazerlo as tres fazes. // Tú entrra con los menos de partes de oryente [...], / entre la otrra faz de parte d'oçidente [...]. // Entrre el otrra terçera de partes d'aquilón, / vençremos, non lo dubdes, a este brravo león") ${ }^{47}$.

Los vaticinios de Merlín, de acuerdo con los testimonios conservados, penetran durante la segunda parte del xiv en la literatura de Castilla. Dos se intercalan en el Poema de Alfonso XI, uno aparece en la Crónica del rey don Pedro. Todos, por estar atribuidos a Merlín, indican su procedencia; todos se apoyan en animales simbólicos, y en todos se explica su función y su significado. Sin embargo, se distinguen entre sí por su extensión y por su designio. Se caracteriza el primero por su brevedad:

Aquesto dixo Melrrín, el profeta de Oriente.

Dixo: el león de Espanna de ssangre fará camino, matará el lobo de la montanna, dentro en la fuente del uino ${ }^{48}$.

45 Primera crónica general de España, ed. Ramón Menéndez Pidal, Madirid, 1955 , t. 2, p. 360 y 487.

46 Poema de mio Cid, ed. Menéndez Pidal, Madrid, 1951, p. 128.

47 Poema de Fernán González, ed. A. Zamora Vicente, Madrid, 1946, pp. 72, 123, 124-125.

48 Poetas castellanos anteriores al siglo $x y$, ed. F. Janer (BAE, t. 57), p. 484 (estr. 242-243). Continúa el autor de esta manera: "El león de la Espanna / fue el buen rey çiertamente, / el lobo de la montanna / fue don lohan el ssu pariente. / E el rrey quando era ninno / mató a don lohan el Tuerto, / Toro es la fuente del vino / a do don Juan fue muerto" (estr. 245-246). 
El episodio, que refiere la muerte de don Juan el Tuerto, cierra el contraste que entre el rey y la nobleza se había levantado ${ }^{49}$. Desarrolla así el motivo de la tiranía en oposición a los monarcas, pero expresa también las circunstancias de Castilla, la pugna que permite por el momento el triunfo de la corona.

El segundo vaticinio, de una longitud considerable (veinte estrofas, más cinco que lo introducen y diez que a continuación lo explican) ${ }^{50}$, asegura el triunfo para Alfonso en la batalla del Salado. Enfrenta, apoyándose en los animales simbólicos consabidos, a dos reyes cristianos con dos monarcas musulmanes: al rey de Castilla ("El león coronado [...] / de Castiella e de León") y al rey de Portugal ("El otrro, león dormiente [...] / que llaman de Portogal") con el rey de Marruecos ("El brauo puerco espín [...] / rrey de Benamerín") y con el rey de Granada ("Rrey de Granada fue el dragón"). Así, la segunda profecía, al anunciar la meta reconquistadora y dirigir hacia ella, continúa el motivo más importante de la tradición peninsular; lo presenta, empero, con una forma diferente, y lo sostiene con un andamiaje simbólico que antes no había utilizado.

El vaticinio que se intercala en la Crónica del rey don Pedro, y que alude a la muerte del soberano, presenta unas características especiales. Es breve su formulación, aunque son muchas las explicaciones que lo acompañan: "En las partidas de Occidente, entre los montes e la mar, nascerá un ave negra, comedora e robadora, e tal que todos los panares del mundo querría acoger en sí, e todo el oro del mundo querrá poner en su estómago; e después, gormarlo ha, e tornará atrás, e non perescerá luego por esta dolencia [...]. Caérsele han las alas, e secársele han las plumas al sol, e andará de puerta en puerta, e ninguno la querrá acoger, e encerrarse ha en selva e morirá y dos veces, una al mundo e otra ante Dios, e desta guisa acabará" (BAE, t. 66, p. 586). Además, aunque se atribuye a Merlín directamente el vaticinio, y aunque derivan de Merlín su tono y alguno de sus elementos, la imagen sobre la que se levanta, las explicaciones que lo ilustran y el sentido que en él se encierra proceden de los comentarios que San Gregorio dedica a Roma en una de sus homilias: "Contigit ei quod de Judaea novimus per prophetam dictum: "Dilata calvitium tuum sicut Aquila» (Mich. I, 16). Calvitium quippe hominis in solo capite fieri solet, calvitium vero Aquilae in toto fit corpore, quia cum valde senuerit, plumae ejus ac pennae ex omnibus membris illius cadunt. Calvitium ergo suum sicut Aquila dilatat, quia plumas perdidit, quae populum amisit. Alarum quoque pennae occiderunt, cum quibus volare ad

49 Lil contraste, que se estableció casi en el comienzo, se viene levantando sobre una serie de digresiones y de episodios. Véase. por ejemplo, los que comienzan en las siguientes estrofas: 72, 80, 91, 168.

50 Ed. cit., pp. $531-532$ (estrofas 1807-1811). 
praedam consueverat, quia omnes potentes ejus exstincti sunt, per quos aliena rapiebat"'51. Y dice la crónica, cambiando el sentido de las afirmaciones de San Gregorio para referirlas a las circunstancias castellanas, acentuando la diferente actitud que ante la nobleza adoptaron don Pedro y don Enrique de Trastámara: "Otrosí dice [la profecía] que se le secarán las péñolas e se le caerá la pluma [...]. Las péñolas con que los reyes ennoblescen a sí mesmos, e amparan e defienden sus tierras e sus estados, son los omes grandes en linages e en sangre, que son sus naturales, porque éstos son comparados e llamados alas con que los reyes vuelan de unas tierras a otras [...]. $\mathbf{E}$ por ende, deben mucho afanar los reyes por que entre ellos e los nobles en sangre non haya desmano a culpa del rey [...]. E desto, todo por tu ventura [se dice al rey don Pedro] muéstrase contra ti lo contrario, por lo qual temo que la profecía quiere cerrar en ti de grado en grado" (p. 587). No es de extrañar la relación con San Gregorio, especialmente teniendo en cuenta que es el canciller López de Ayala el que introduce en la crónica la profecía ${ }^{52}$. Justifica ésta el regicidio; además, aprovechando los crímenes de Pedro y las afirmaciones que sobre el fin del mundo habia pronunciado San Gregorio, construye un doctrinal de reyes. Doctrinal que, sin embargo, y en esto el Canciller y San Gregorio se diferencian ${ }^{53}$, no busca el arrepentimiento del monarca, sino la exaltación del programa político que con Enrique II se establece en Castilla.

A finales del xıv, si no mienten los documentos conservados, comenzó a propagarse en Castilla la literatura de Merlín. El Baladro del sabio Merlin incluye un capítulo de profecías que los traductores anteriores a veces desconocieron ${ }^{54}$; capítulo de importancia, sin embargo: porque la fuente europea más antigua lo presenta, y porque influyó después en muchos vaticinios y pronósticos ${ }^{55}$. La Demanda del saneto Grial, que lo ignora aunque recoge una versión del Balandro, asegura su influjo al añadir un capítulo que se sirve de sus elementos ${ }^{56}$. No faltan, claro está, diferencias: el material simbó-

51 In Ezechielem, II, vi, 23 (PL, t. 76, col. 1011). El águila que utiliza San Gregorio para referirse al imperio de Roma se convierte en el ave negra del Canciller para referirse a los crímenes y a la tirania del rey don Pedro, y para atribuir en cierto modo su muerte a su destino.

52 Recuérdese el interés y la insistencia con que López de Ayala se acerco a la obra de San Gregorio. No sólo tradujo y glosó en prosa y en verso sus Morales, sino que además las doctrinas del santo justificaron a menudo su postura y sostuvieron con frecuencia sus argumentaciones.

53 Las afirmaciones de San Gregorio buscan, como he indicado anteriormente, la renovación de sus contemporáneos.

${ }^{4}$ Me refiero al capítulo 9 del Baladro del sabio Merlin, ed. Justo García Morales, Madrid, 1956.

${ }^{55}$ Se trata del libro VII de la Historia Regum Britanniae de Godofredo de Monmouth; del cual precisamente he utilizado antes la materia.

56 Aparece añadido, y retocado sin duda posteriormente, al final de la pri- 
lico se reduce a los animales que esconden a los reyes, y a las perífrasis que disimulan la geografía. Se modifica también el movimiento sujetándolo al ritmo conquistador de la tradición profética castellana; y se dirige de ese modo hacia los objetivos precedentes. Pero, a la vez, este movimiento, al impacto de las doctrinas de Joaquín de Fiore, introduce nuevos ideales, y empuja hacia nuevos objetivos. De ahí el rumbo peculiar que en la Demanda adquiere la historia de Castilla.

Comienzan las profecías aludiendo a los visigodos para proyectar hacia el pasado la historia de los españoles y la línea de sus reyes; confieren de esa manera a la una y a los otros antigüedad y prestigio: "Sabed que dos reyes godos descendirán en España de parte de oriente, que de Dios serán embiados [...]. Y éstos señorearán las partidas de España, y de aquellos godos descendirán los reyes de las partidas de España; cada vno por cuento, vno empós de otro" (p. 157). Presentada y ennoblecida de ese modo la raíz histórica de los personajes, se alude a los reyes don Rodrigo y don Pelayo para identificar con la reconquista su quehacer y su destino: "En aquel tienpo se perderá vn rey de los godos que será rey de España $[\ldots]$, por lo qual [...] España llegará al punto de se perder. Y será destruyda en aquel tienpo hasta los puertos, de la gente mala e descreyda [...]. Y [...] se ayuntarán las gentes de las tierras de España e farán rey entre sí [...], e con este rey e con su linaje c generación defenderá esta conquista" (ibid.). Tras suministrar, así, al destino de los españoles un cauce y una meta, se limita geográficamente, aludiendo a Fernán González y al nacimiento de Castilla, el campo de sus hazañas: aparecerá "vn león que cometerá las gentes brauas con el ayuda del señor muy alto, e partirá las tierras con sus vasallos, e llamarse ha cabeça de condado. E con este conde e con su linaje se defenderá esta conquista de España fasta oue será cabeça de reynado" (ibid.).

En efecto, por ese cauce, y sin desbordarlo, transcurre la historia de Castilla; se ensanchan las fronteras de victoria en victoria, hasta llegar a un glorioso presente en el que la reconquista se concluye: "Dios enbiará en la parte del león su ayuda, e las crueles bestias se espantarán [...]. E assí se quedarán las tierras libres, e cobrarlas ha este rey león de España" (pp. 160-161). Hasta ahí, pues, el movimiento continúa las directrices tradicionales; pero, a partir de ahí, los vaticinios, que aluden al futuro real de la historia de Castilla, desbordan el cauce precedente. Suena entonces para España la hora del imperio: "Y en este tienpo descenderá el imperio en el reyno de España” (p. 161). El rey león se multiplica en hijos que

mera parte de la Demanda del sancto Grial. Puede verse en Libros de caballerias, ed. A. Bonilla y San Martín, parte I (NBAE, t. 6), pp. 155-162. A continuación indicaré la página, entre paréntesis, en el texto. 
atraviesan los mares y que se extienden por el universo. Asia, Africa y Europa les ofrecen sus tronos: "Dixo el sabio Merlín que este rey león de España aurá vn fijo [...] y éste será llamado cieruo corredor de la gran ventura, y éste sojuzgará todas las tierras de África $[\ldots]$, Este rey león aurá otro fijo [...], y éste será llamado falcón bolador de la gran ventura [...], y éste aurá cinco reynados en la ysla de Asia [...]. Aurá este rey de España otro hijo [...] y éste será llamado brauo león [...], e la su morada será en la tierra santa de Jerusalem [...]. Aurá este rey de España vn hijo [...] e será llamado casa de sapiencia, y en éste quedarán los cinco reynados de España" (ibid.). Suena también entonces, con el triunfo de Castilla, la hora gloriosa de la Iglesia: "En aquel tienpo será este rey león señor de toda España, y será alférez de la yglesia de San Pedro, e será su defensor e guardador. Y en aquel tienpo aurá mucho amor con la yglesia de Jesuchristo. $\mathrm{Y}$ en aquel tienpo será la yglesia de Sant Pedro más honrada, e más ennoblecida, e más ensalçada que en otro tienpo" (ibid.). De ese modo los vaticinios de Merlín introducen los ideales de Joaquín de Fiore. No debe extrañar, por eso, el cambio de directrices; cambio que, por otra parte, se adecúa a las circunstancias de su época. Castilla, en la cúspide de su poder, se prepara así a concluir la tarea reconquistadora, decidida a llevar sus fronteras más allá de los límites peninsulares.

Un gran número de profecías aparece en el Cancionero de Baena; profecías que recogen, por otra parte, casi todos los propósitos que hemos enumerado: como doctrinal de príncipes dirigen a menudo a los monarcas; como aviso ante la situación desordenada del presente aluden a los errores de Castilla, y buscan, por caminos distintos, la rectificación y la enmienda. Así, durante la menor edad de Juan II adelantan su próximo reinado, lo presentan como príncipe vengador y providente, como caudillo feroz y justiciero:

Después de los veynte será reuestido en justa justiçia, virtud santa, pura, esfuerço e franqueza, verdat e cordura; serán sus arneses del muy alto vngido.

Por estas virtudes será conoscido, e dende adelante lo rreçelarán el jaualí crespo e el viejo alacrán que tractan en pazes buscando rroydo ${ }^{57}$.

En los momentos de peligro, cuando la rectificación es difícil, aseguran las profecías, con palabras próximas a las que Deschamps había pronunciado, calamidades y desgracias (Villasandino, ibid., t. 1, pp. 198-199) :

57 Cancionero de Baena, ed. J. M. Azáceta, Madrid, 1966, t. 2, p. 362 . El poema, que pertenece a Villasandino, muestra en su comienzo una clara relación con las profecías interpoladas en la Demanda. 
Amigos, ya veo acercarse la fyn segumt las señales se uan demostrando; los muy fuertes muros se uan derribando, peresçen las flores de todo jardín. Verdat me paresçe que dixo Merlín en vnas fyguras que puso entricadas que por cruel fuego seryan soterradas las alas e plumas del grant serafyn.

A menudo también, las profecías aducen materiales y objetivos que Joaquín de Fiore había utilizado, para indicar con ellos, por medio del elogio del monarca, el poder y el prestigio de Castilla. Dice así, por ejemplo, García de Córdoba del recién nacido Juan II (ibid., t. 2, p. 450): "Este será el muy fuerte pyno/que todo el mundo terrná en su pesso"; y añade don Moisés, cirujano de Enrique III (ibid., t. 2, p. 454):

\author{
En Aragón e en Catalueña \\ tenderá la su espada \\ con la su rreal mesnada; \\ Nauarra con la Gascueña \\ tremerá con grant vergüeña; \\ el rreyno de Portogal \\ e Granada, otro que tal, \\ fasta allende la Çerdeña.
}

$\mathrm{Y}$ dice años más tarde, también en relación con Juan II, Gonzalo Martínez de Medina (ibid., t. 2, pp. 742-743) :

Gozen e tomen las altas conquistas, apuren las mares los moros vençiendo [...], en Jerusalem su sylla poniendo, rreçibiendo corona de alto enperador [...].

Ca segund ley en las profeçías por él ha de ser aquesto acabado. Aurá luenga vyda, e todos sus días será vençedor o vienaventurado ${ }^{58}$.

Intentan también las profecías despertar a los reyes, dirigirles hacia una actividad reconquistadora que concluya el interrumpido camino, buscando hacer así del presente la culminación del pasado y el ejemplo del futuro. Proyectándose hacia el porvenir entonces, hacia el momento glorioso de la toma de Granada, sirvieron para guiar al príncipe al unir con el de la reconquista su destino, para enderezar sus pasos al establecer como meta de sus esfuerzos la cul-

58 Charles F. Fraker, Jr., "Prophecy in Gonçalo Martínez de Medina", BHS, 43 (1966), 81-97, estudia esta y otras muchas profecías. 
minación de la historia castellana. Dice así Villasandino de Juan II, precisamente cuando terminaba su minoría (ibid., t. 2, p. 363) :

De allí partirá, su pendón tendido,

el bien costelado con buena ventura;

el pueblo agareno de mala natura

será conquistado e todo estroydo.

Las profecias se multiplican al advenimiento de Isabel y Fernando y a medida que se adentran sus ejércitos en el reino de Granada. De ahí que tras la conquista de Ronda presente Mosén Diego de Valera a don Fernando como el príncipe esperado y prometido, príncipe al que no sólo se reserva la realización del destino de Castilla, sino además la función que Joaquín de Fiore y sus discípulos habian reservado a su monarca:

Muy alto e muy poderoso Príncipe, Serenísimo Rey e Señor: Claramente se muestra nuestro Señor querer poner en obra lo que de muchos siglos acá está profetiçado de vuestra muy ecelente y esclarecida persona, es a saber, que no solamente estas Españas pornés debaxo de vuestro cetro real, mas las partes ultra marinas sojuzgarés en gloria y ensalçamiento de nuestro Redentor e acrecentamiento de la cristiana religón, y en grande onor y ecelencia de vuestra Corona real [...]. ¿Quién es que no esté atónito en ver e oír en espacio de veinte e dos días, Vuestra Alteza aver debelado, vencido e sojuzgado el tercio del reino de Granada $[\ldots]$ ? Pues qué diremos aún, vitoriosísimo Príncipe, sino que Dios es con vos, y en virtud vuestra e de la serenísima princesa Doña Isabel, Reina e Señora nuestra, quiere destruir e desolar la pérfida mahomética seta? [...] Así, Señor, es de creher que Dios vos ama e vos fiço tales nacer, no sola. mente para restaurar, reformar e defender estos reinos, mas para debelar e destruir a todos los enemigos de la Sancta Fe Católica ${ }^{59}$.

Nada de extraño hay en realidad en tales afirmaciones, pues Castilla venía sintiéndose (dentro de una vieja tradición que a través de San Isidoro enlazaba con los autores del Imperio, y con los autores árabes a través de Alfonso el Sabio) cúspide y cabeza de Occidente, con sólo el Oriente por encima de su majestad y de su prestigio. De ahí que fray Martín de Córdoba se lo recordara a Isabel unos años antes, y que repartiera, al recordárselo, entre Dios y el rey de España el universo, para que la vieja inferioridad de Occidente aumentase, y no disminuyera, la gloria de Castilla:

Pues Dios, que en el vientre de la madre dio a predestinó a ésta para reina de tan noble reino como España, más obligada es a lo

59 "Epistola que Mosén Diego de Valera enbió al rey don Fernando, Nuestro Señor, después que ovo tomado la cibdad de Ronda", en Prosistas castellanos del siglo $x v$, t. 1, ed. M. Penna (BAE, t. 116), p. 31. 
amar que otra ninguna; ca, los beneficios crecientes, crece el amor. Así que todas las mugeres son tenidas de amar a Dios e mucho más las reinas e princesas, entre las quales resplandece la nuestra, a la que está aparejado tan bienaventurado reino como España. Dizen que el mundo tiene dos partes principales: Oriente e Occidente. En Oriente puso Dios su silla, haziendo allí el Paraíso eternal. En Occidente puso la silla del rey de España. Donde parece que Dios partió el reino de la tierra con nuestro reyio.

Así, recordando imágenes de Horacio ("Caelo tonantem credidimus Iovem / regnare; praesens divus habebitur / Augustus. ..") ${ }^{61}$, se realizan por fin las viejas profecías, se cumplen en Granada las que a través de una azarosa historia sostuvieron a los castellanos; se escuchan desde entonces solamente aquéllas, más modernas, que ofrecían un futuro universal a su destino, futuro universal que desde la gloria del presente se ve ya como español y como realizado.

Case Western Reserve University.

Joaquín Gimeno Casalduero

60 Jardin de las nobles doncellas, en Prosistas castellanos del siglo $x \mathrm{v}, \mathrm{t} .2$, ed. F. Rubio (BAE, t. 171), p. 95.

${ }_{61}$ Od., 111:5, 1-4. Seguimos la edición de Guil. Dillenburger, Opera omnia, Bonnae, 1881. 